\title{
Problems Encountered in Femanine Primary School Headship in Marange in Mutare District.
}

\author{
${ }^{1}$ Chikwature, W., ${ }^{2}$ Oyedele, V. \\ ${ }^{1}$ Mutare Polytechnic, Research Department, P.O. Box 640, Mutare. ${ }^{2}$ Africa University P.O. Box 1320, Mutare \\ whatmorec@gmail.com, oyedelev@africau.edu
}

\begin{abstract}
The purpose of this study was to investigate and identify the problems faced by female head teachers in the management of primary schools in Marange area in Mutare district in Manicaland province. The mixed method research design was used which incorporate both qualitative and quantitative methods. The target population in this study were the female head teachers in Marange area in Mutare district, teachers and the Education Officer of Marange area in Mutare district. Marange area in Mutare district has 52 primary schools, of which seven (7) are headed by female head teachers. The researchers used questionnaires and interview guides for collection of data. The interview was targeted for female head teachers and Education Inspector of Marange area in Mutare district. The data that was obtained was both quantitative and qualitative. Majority of the teachers $(75.0 \%)$ said that their perception towards their head teachers was good. Majority of the teachers (87.5\%) noted that psychological traits do not bar the head teachers from performing school duties effectively. All of the teachers noted that the students accorded male and female teachers at the same level of respect. The following conclusions were drawn. Female head teachers are positively viewed by their teachers and students and are approachable since they encourage them to work to attain their goals in schools. Cultural and social barriers do interfere with the management of school affairs. Half $(50 \%)$ of the head teachers said there was no role conflict between domestic and professional roles while $50 \%$ of head teachers felt that there was conflict. On the psychological factors influencing the head teachers' performance, $87.5 \%$ of the teachers said that biological traits did not bar the head teachers from performing school duties. This was because they had a teaching experience, were assertive and aggressive. The study recommended that since female heads were positively viewed strongly by teachers, there is need for them to be given more posts of leadership in primary schools. Thus, female head teachers are effective hence, they are able to achieve the goals of their respective institutions. Although cultural and social barriers may interfere with the management of school affairs, there is need for female heads to be encouraged to achieve leadership positions since they can manage the roles of leaders through mentorship.
\end{abstract}

Key terms: problems, feminine, primary headship

$\begin{array}{ll}\text { BEAM } & \text { Basic Education Assistance Module } \\ \text { DEO } & \text { District Education Officer } \\ \text { MOE } & \text { Ministry of Education } \\ \text { MHTE } & \text { Ministry of Higher and Tertiary Education } \\ \text { PLAP } & \text { Performance Lag Address Programme } \\ \text { PSE } & \text { Permanent Secretary of Education } \\ \text { PED } & \text { Provincial Education Director } \\ \text { RBM } & \text { Results Based Management } \\ \text { TIC } & \text { Teacher-in-Charge } \\ \text { ZIMSEC } & \text { Zimbabwe Schools Examination Council }\end{array}$




\section{Introduction}

Leadership is generally regarded as the key factor in making a difference to the success of schools and in promoting the learning of their students. With increasing pressure for a higher quality of primary schools, the head teacher plays a vital role in creating an effective school environment. School leadership in Zimbabwean schools like in any other country is the function of the head teacher, the female head teacher included. The purpose of this study is to investigate and identify the challenges faced by female head teachers in the management of primary schools in Marange area in Mutare District. The success of any school depends on how effective the head teacher is as an administrator. The status of the female head teacher is also very central and very complex. They carry out managerial activities because in their leadership, they try to accomplish the school's goals and objectives. In the execution of their managerial duties, the female head teachers are faced by a myriad of challenges ranging from gender discrimination, discipline issues amongst the staff and students among others. Both male and female head teachers face similar challenges in the management of primary schools but at times differ due to dual responsibilities done by female head teachers. Some studies attempt to explain the barriers that women face as they enter educational leadership such as, culture, family and discrimination. Other studies focus on administrative factors such as remuneration, the workload, stress, and others. Most of these studies have concluded that women are under-represented in educational leadership, and some indicate that they face various challenges in their aspirations to attain and maintain these positions. Fewer studies, however, have provided limited insights into the nature of the problem's women face in administering schools efficiently and effectively (Chelimo and Wasanju, 2007). Most of these studies involve institutions of higher learning and secondary schools and limited studies have been conducted on the challenges faced by female school head teachers of primary schools.

As this evolution continues, the question arises as to whether or not male and female principals lead schools in a similar or different manner, and secondly if the gender of the principal alone has an impact on the perceived leadership abilities of the principal. Tyree (1995) as quoted by Celikten (2006) suggested that there exists a perception that women lack support from the staff, parents and community that does not exists with male principals. Busolo (2007) suggested that leadership through the perspective of a woman is very different from the traditional view of leadership. These perceptions and attitudes play a critical role on how principals perceive themselves as being an effective educational leader and how, the people these principals are leading, primarily teachers, perceive their leadership as well. Shakeshaft (1989) as quoted by Hoff and Mitchell (2008) found that teachers preferred working for male principals regardless of their gender. Research studies in Turkey and USA found that in a number of occasions, gender plays a very limited role as far as leadership is concerned.

However, further research conducted by Grant (2008) suggests that female principals may face a dilemma that finds an imbalance between leadership roles and expected gender roles. Khumalo, 2006.conducted studies in the Republic of South Africa on "Challenges faced by women as school managers in Warmbaths area." These studies showed that the challenges faced by female managers that hinder them from achieving true parity in relation to their male colleagues could be divided into three categories; those challenges within the school, those outside the school and those within the person herself. Wikham (2007) believes that intrinsic, internal or personal barriers that influence the life of women are generally regarded as the inadequacies, which are within women because of their femaleness.

A study conducted by Parsaloi and Steyn, (2013) in Kenya worked on the representation of women in leadership positions in Kenya's rural primary schools. In particular, it explored the educational leadership experiences of women working in schools in the rural areas within Kajiado County. The key findings revealed administrative challenges, which included the grievances of the parents, limited resources, and issues with accountability, time-management and the handling of difficult teachers. Personal challenges included wavering self-confidence, problems with trying to balance work and social lives, as well as home-work conflicts. The findings revealed the participants' inadequate preparation for their leadership roles, and society's initial skepticism on women's school leadership. The study also revealed women's reluctance to take 
up leadership positions, as was evidenced by their reluctance in applying for the positions. The study found that the participation of women in primary school leadership positions could be enhanced by means of attractive remuneration, effective mentoring, positive role-models, programmes for the preparation for leadership, and the assurance of limited geographical movement on promotion. There are several dilemmas that complicate roles of female leaders in Zimbabwe, in their day to day running of duties. Women have to balance work and family responsibilities, yet they have the same amount of time as their male counterparts. Women face cultural and social barriers in school management. Stereotyped notions about women leadership constitute a major challenge to female head teachers (Kamau, 2006). Stakeholders perceive male head teachers more favourably than female head teachers. Teachers prefer to work for male head teachers since they have a low perception for female head teachers. Some female head teachers perceive themselves as less leaders compared to their male counterparts (Kamau, 2006). All these were issues of concern in this study.

Although the presence of women in leadership has been researched in numerous overseas countries, very little data exists with regard to challenges faced by females as primary head teachers of rural schools in Africa. For example, in Zimbabwe out of the ten provinces data concerning challenges or dilemmas faced by female primary school head teachers has been indicated for Masvingo and Harare Provinces. Makura (2011) carried a research with female heads in Masvingo province in Zimbabwe. His research shows that female primary school heads face unique challenges in their substantive positions. A sample of nineteen female primary school heads in the Masvingo province of Zimbabwe responded to a quest/view seeking their perceptions on their workrelated challenges. This study was part of a larger study on females and school leadership. Results revealed that organisational factors, culture, women's personalities and colonial legacies are obstacles challenging the effectiveness of females in school administration. Specifically, shortage of financial and material resources and teachers' negative attitudes towards female primary school heads were cited as the major impediments to effective school administration. However, the government is still expected to continue appointing more women to school leadership positions despite the identified challenges.

Another study was conducted by Mapolisa and Madziyire in 2012 and qualitatively examined dilemmas that female school leaders in female headed primary schools in Kambuzuma, Warren Park and Kuwadzana areas of Harare Province face. The study found out that Zimbabwean women have been socially, politically, economically and culturally marginalised for a very long time. Female school leaders in spite of their high educational qualifications raise children and manage homes. They also lacked the support of other fellow female subordinates. The study found out that social and cultural factors intervene to form a barrier to women advancement.

From the findings of the above studies, sex-role stereotyping, cultural traditions, negative perceptions from teachers and stakeholders to female head teachers, dual responsibility of motherhood and school manager are major challenges faced by female principals in the management of primary schools. In Africa the studies reviewed here were conducted in Kenya, South Africa and in Zimbabwe in Masvingo and Harare provinces. In an attempt to understand the plight of women leaders in primary schools, it is deemed necessary to take a look at the status of women leadership in Zimbabwe mainly by carrying out a similar research on the challenges faced by female primary school head teachers working with Marange area in Mutare District. No studies have been conducted on challenges faced by female head teachers in the management of primary schools in Marange area in Mutare District and this study wishes to fill in the gap. Marange area in Mutare District is one of the four circuits in Mutare District, the most popular district in the country, and the circuit is comprised of rural schools. When looking at Marange area in Mutare District, out of 52 primary schools only 7 schools are headed by females.

Though some studies on challenges and dilemmas faced by female head teachers have been conducted in Zimbabwe in Masvingo and Harare Provinces, a very wide gap still remains for more researches to be conducted in other provinces throughout the country on challenges faced by female school head teachers in the management of rural primary schools. The present researchers have noted from the above different research findings that no research on challenges faced by female primary head teachers has been conducted 
in Marange area in Mutare District. Therefore, there is need to carry out a research to find out challenges faced by female primary school head teachers in Marange area in Mutare District. Though similar researches were done by Makura in Masvingo, in 2011 and by Mapolisa and Madziyire in 2012 in Harare province respectively on challenges and dilemmas faced by female primary school head teachers, it can also be conducted completely to different participants and in a completely different geographical area, in particular, with rural primary schools. It is of great importance to understand challenges faced by female primary school heads in the rural areas.

\section{Research Questions}

This study on the problems encountered in feminine primary school headship in Marange area in Mutare District was guided by the following research questions:

1. What institutional challenges are faced by female head teachers in the running of primary schools?

2. Do cultural and social challenges interfere with management of primary schools headed by female head teachers?

3. What is the perception of teachers and other stakeholders towards female head teachers?

4. How do psychological or personal challenges affect female head teachers in the running of primary schools?

5. What is the training and development needs required by female head teachers for effective management of primary schools?

\section{Materials and Methods}

This study employed a descriptive survey design. This design was deemed suitable for this study since the study would, through data collection from the respondents, assess attitudes, opinions and draw conclusions based on the findings. The research required a methodological approach which places the women head teachers at the centre of the inquiry, by allowing them to articulate their experiences. It also helped the researchers to gather information on challenges faced by female head teachers in management of primary schools in Marange area in Mutare District.

\section{Population and Sampling}

There are 52 primary schools in Marange area in Mutare District and out of these seven are headed by female head teachers. As the researchers happens to be one of the female primary school head teachers in this Circuit, she decided to work with all the other seven female headed schools since the population was not that big. This category of respondents was targeted since they are consumers and specialists of primary education and thus are involved in one way or the other in the management of primary schools. The researchers also worked with 48 teachers from these schools.

Since there are only seven primary schools headed by female head teachers, the researchers carried out the research in all the other seven schools which forms eighty-five-point seven percent of the schools headed by female head teachers in the circuit. Having proposed to interview seven women head teachers and to also collect data from teachers and female head teachers using questionnaires, contact was made with the Ministry of Primary and Secondary Education, from whom a list of all the schools headed by females was obtained. The researchers then proceeded to determine the location of the seven schools. One of the female head teachers was on vacation leave and special arrangements were made to conduct an interview with her. The next task was to contact the seven female head teachers. Letters of introduction were written beginning of October 
2015 and left for collection on a heads' meeting. Their telephone numbers were also collected from the Education Office for the purpose of the phone calls that followed the introduction letters.

The main type of sampling was purposive sampling. The researchers used purposive sampling in the selection of the female head teachers. All the other seven schools except the researchers' school were purposively sampled. Random selection was also done to sample four male teachers and four female teachers from each and every one of the seven schools using odd and even numbers. Those who picked even numbers then qualified for the study. No school had males or females exceeding nine, so the researchers could easily get four males and four females to participate in the study. Initially all the teachers from the seven schools had the required qualifications and good working experience to which it was likely to lead to the identification of the challenges faced by female head teachers. This was important because it is this sample which the researchers supposed could give relevant information on the challenges faced by female head teachers in the running of primary schools.

\section{Data Collection Instruments}

The researchers used questionnaires, interview guides and observations for collection of data and the researchers herself as the major data collection instrument. Questionnaires were administered to the head teachers and teachers and interviews were conducted to the head teachers and the education officer for Marange area in Mutare District. Observations schedules were used when the researchers visited the schools.

In accordance with the qualitative research paradigm, the researchers were the major data collection instrument. She was the primary instrument for making sense of the phenomenon under investigation.

\section{Questionnaires}

The questionnaires were used to collect data from the head teachers and teachers. It is deemed fit since it makes anonymity possible since the respondents were not required to identify themselves and this encouraged the respondents to give information freely without fear. The questions in the questionnaire were standardised to enable the researchers to get the correct information needed to answer the research questions. Both closed and open-ended items were used in the questionnaire which generated quantitative and qualitative data respectively. Questionnaires were administered on the day when the researchers visited the school to conduct an interview with the head teacher. Data collection was done during lunch time, the interview taking about thirty minutes and the questionnaire taking about forty minutes to be completed. It was the interview that was conducted first and then both the head teacher and the sampled teachers filled in the questionnaires. The questionnaire was divided into three sections: thus, for demographic information; school management and; perceived challenges which were sub-divided into institutional challenges, sociocultural challenges and psychological or personal challenges. The first section had five questions and the second section had seven questions while the third section had eight questions. In the third section three questions were for institutional challenges, two for socio-cultural challenges and three for psychological challenges. Each section was comprised of both open and closed-ended questions. All closed-ended questions were answered by all participants. Different opinions were given to the open-ended questions though some sections were left uncompleted. Overall no question was left unanswered.

\section{Interviews}

In order to establish a framework around the interviews and to focus on specific issues regarding headship, the interviews were semi-structured, with an interview-guide, containing a list of questions that needed to be covered by the interview, being prepared beforehand. The questions were open-ended to encourage meaningful responses from the interviewees. Semi-structured interviews are advantageous in that they are flexible. The use of open-ended questions enabled the researchers to get a complete and detailed understanding of the issues that were researched. The researchers used an interview guide which is a set of questions that an interviewer asks when interviewing respondents. The interview guide was administered to 
the seven female head teachers. Combined with observation, interviews allow the researchers to understand the meaning that everyday activities hold for the female head teachers. To understand the female head teachers' leadership experiences and the challenges they face required interactive field research, calling for face-to-face interaction between the researchers and the selected female head teachers. This was achieved by means of interviews, which allowed for an in-depth discussion with the female head teachers, thus enabling the researchers to collect data on how the individual female head teachers made sense of their leadership experiences and challenges they face. This technique, although time-consuming, provided the researchers with the opportunity to obtain qualitative data in a manner that has the benefit of providing an overall question and focus for the interviewer, yet also providing the interviewees with the opportunity to express their views. Interviews were conducted on the same day when questionnaires were administered except for one school where the female head teacher was on vacation leave and the head teacher was interviewed at the District Office successfully after making some special arrangements. The interview guide was divided into three sections, thus, 'preparation for leadership' with seven questions, 'work experience' with five questions and 'concerns' with three questions. Additionally, the interview was not restricted to questions that the interviewer initially intended to pose because issues that arose during the interview process, and were deemed relevant to the research, were pursued. In this study the respondents also had the opportunity to express their views, explain their individual perspectives and expand on their answers. The interviews lasted approximately forty minutes per participant, and five of them were conducted at the participants' workplace. Each interview was transcribed, and eventually the transcribed work was confirmed with the participants through phone calls. It was expected that through the interviewing process, an enriched understanding of female headship and the challenges they face in the running of the primary schools, would emerge, one that would assist in enhancing the participation of females in primary school headship.

\section{Observation}

One of the main goals of conducting interviews at the participants' places of work was for the researchers to gain an understanding of the climate and the culture of the school, as well as a first-hand observation of the identified phenomenon, namely female school headship and the challenges they face. Unstructured observation was also carried out in an attempt to help the researchers understand the behaviour patterns of the female head teachers in their physical and social settings. The researchers focused on the involvement of the head teacher with the teachers and students, and also with visitors. Attention was also given to the approach road, the signage, the ECD play centre, school projects, the staffroom, the 'talking walls' in the head teachers' offices and the school's notice boards, as these were likely to reveal certain aspects in respect of the school, such as performance, the teachers, and awards given to the school. Observations were likewise done during the interview process, in order to identify the nonverbal body language and facial expressions of the interviewee to help interpret the verbal data". Observations that needed clarification were discussed with the head teachers after the formal interviews, and later when the data were being analysed. When the researchers interviewed one head teacher at the District Education Office some clarification on what the researchers had observed at the school was made. The researchers were keen to check on the congruence between the respondents' reactions and the observations that were made.

\section{Result and Discussion}

The study set out to establish the challenges faced by female primary school head teachers in Marange area in Mutare District. Qualitative strategies were used in this study as they are seen to be effective in addressing social issues that affect individuals because by using the qualitative methods, the researchers were able to collect data and explain phenomena more deeply and exhaustively. A description of all the activities and procedures that were undertaken during the empirical study were outlined. This chapter presents a description of analysis of data, presentation, interpretation and discussions. The study was on the challenges faced by female head teachers in the running of primary schools in Marange area in Mutare District, Zimbabwe. The researchers collected data from observations, individual interviews with female head teachers and from questionnaires that were issued to teachers and female head teachers. 


\section{Challenges faced by female head teachers}

School female head teachers face various personal and organisational challenges in the course of their work (Pont, et al. 2008). The challenges faced by female managers that hinder them from achieving true parity could be divided into three categories; those challenges within the school, those outside the school and those within the person herself. Therefore, in this study the challenges were divided into three different groups that are institutional challenges, socio-cultural challenges and psychological or personal challenges.

\section{Delegation of duties to teachers}

The teachers were also asked to provide information on the delegation of duties by the head teachers. It was revealed by all teachers that all the head teachers have a tendency of delegating duties to subordinates. All teachers were involved in the running of schools since they indicated that their heads delegate some duties to their subordinates. Teachers indicated that the duties which are usually delegated by their heads were on distribution of school stationery, school textbooks and other assets like sports and garden items. Some teachers even indicated that they are given the responsibility of looking after school grounds. Some also indicated that they are appointed as masters or mistresses in the following areas; school garden, school health, BEM and GEM. Some were even appointed to be in charge of PLAP and ERI programmes.

\section{Leadership style used by the female head teachers as indicated by teachers.}

Leadership styles means simply the patterns of behaviour a leader adapts to plan, organise, motivate and control. It is the extent to which he or she listens, sets goals, and standards, develops action plans, directs others and gives feedback. It was noted that $(62.5 \%)$ of teachers indicated that the head teachers use the combination of the three leadership styles while31.25\% indicated that their head teachers were democratic, and that female head teachers of schools that used democratic leadership styles in their schools had short leadership experience. The minority (6.25\%) showed that the head teachers indicated that the head teachers use autocratic type of leadership. No teacher indicated that head teachers use Laise Faire leadership style. Using a combination of the three will result in the head teacher being effective.

This study also wished to establish if the school organised for training programmes on education management for teachers in schools. On organising for training programmes, the information showed by the teachers the minority (12.5\%) indicated that the school organises for training and $87.5 \%$ indicated that the school does not organise for training programmes. Though some teachers clearly indicated that their schools organise for training programmes on educational management this seems to be lacking with the majority of schools. It was indicated by some teachers that probably the head teachers do not regard such trainings as being important both to teachers and head teachers themselves. The major reason given as to why the schools did not organise training were lack of funds hence only the TICs, the deputy head teachers and the head teachers attended training mainly organised by Mutare District Education Office.

\section{How cultural and social barriers interfere with management of primary schools by female head teachers}

Culture and tradition have a noticeable impact on women managers. Gillard in 2007 defines culture as the habits, traditions and beliefs of a country, society or group of people. The school is an extended organ of the community and cultural beliefs also manifest themselves in the school situation. When educators enter schools, they do not leave behind their cultural belief systems. Some cultural beliefs lead to perception of women as being inferior to men and cannot manage over men. Because of their femaleness, they are thus considered to be weak and not fit for management positions (Gillard, 2007) hence the researchers sought to identify from teachers whether cultural and social issues interfere with management of school affairs. What she got from teachers on culture and social issues and the Majority $(81.25 \%)$ of the teachers indicated that cultural and social issues interfered with the management of school affairs and $18.75 \%$ of them indicated that cultural and social issues did not interfere with management of school affairs. These results show that the 
teachers agreed that there are cultural and social issues that interfere with the management of the school negatively.

The female head teachers were also asked to comment on whether social and cultural issues affect their leadership roles. All the female head teachers indicated that cultural and social issues interfere with their leadership roles. This was also observed in the study by Shakeshaft (2007) as quoted by Hoff and Mitchell in 2008 that women have excellent leadership skills, but often face cultural and social obstacles that men may not face. Tyree in 2008 , also suggested that there exists a perception that women lack support from the staff, parents and community that does not exist with the male principals. What female head teachers need for them to show case their knowledge and skills is support from different stakeholders.

\section{Role conflict between domestic and professional roles}

The researchers sought to find out from the female head teachers if they experience role conflict between domestic and professional roles and the majority (83.3\%) of teachers indicated that they experience role conflict between their domestic and professional roles while only $16.7 \%$ indicated that they do not. This trend shows that most of the respondents were of the view that family responsibility is the main constraint or barrier for women in educational leadership position. Oyedele and Chikwature (2016) believe that the twin demands of career and family affect both men and women, but it is the woman who most often carry the major responsibilities within the home. Men can take their school work home because they have minimal disturbances as compared to women. The housework disturbs women managers who wish to take their school work home.

The researchers also got some information from the female head teachers to find out whether they experience role conflict between domestic and their professional roles. Half (50.0\%) of the head teachers indicated that there is conflict between domestic and professional roles and the other half $(50.0 \%)$ indicated that they felt that there is no conflict between domestic and professional roles. The reasons for indicating that there is conflict between domestic and professional roles was because the head teachers felt that for a female head teacher, school work is so involving and interferes with domestic issues and therefore conflict arises. The professional role is tasking hence much time is dedicated to the students and little time to the family and doubling as a mother and a career woman is not easy and especially when one has to be in school very early in the morning. A related challenge confronting to female administrator relates to role conflict (Mutopa et al 2011). Bureaucratic expectations and one's social agenda may be incompatible. A female head may, for example, be expected to take her sick child, who is attending school at the school she is heading, to hospital during working hours. She may also be required to discipline the same child for deviant behaviour. Her role as principal and parent may cause conflict. The roles of parent, principal and spouse may thus produce conflict for a given woman administrator (Hoy and Miskel, 2011).

Those female head teachers who felt that there was no conflict between domestic and professional roles was because they felt that the head teacher was supposed to balance between the professional and domestic roles, time management is important, having ways of managing stress effectively reduces the pressure from both domestic and professional roles.

\section{How attitudes of staff members and other stakeholders towards female head teachers}

It is good to know what kind of attitude teachers have towards their female head teachers. Wolfram, Mohr and Schyns in 2007, contend that there are prevalent staff prejudices against female leaders. They further argued that female leaders were at risk of receiving less professional respect from their staff than male leaders and staff with traditional gender role and attitudes were prone to have comparatively little professional respect for female leaders.

\section{Perception of teachers towards their female head teachers}


This study also wished to establish the perception of staff members. The researchers asked the teachers' perception towards the female head teachers. Majority of the teachers $(75.0 \%)$ indicated that their perception towards their head teacher was good, while $16.7 \%$ of them indicated that it was fair and $8.3 \%$ of them indicated that it was poor meaning that they perceived them negatively. The perception of the majority of teachers towards female head teachers was quite positive and this enables the female head teachers to feel accommodated and effectively and efficiently manage in the running of primary schools.

\section{How the influence of psychological factors on women with regard to management of primary schools.}

Psychological factors are factors related to how women managers perceive themselves. Coetzer (2004) believes that all management behaviours start from within the individual's deepest self. The way the person behaves is influenced by the way that person views himself or herself. The manner in which women managers view themselves is of paramount importance. Personal challenges included wavering self-confidence, problems with trying to balance work and social lives, as well as home-work conflicts (Parsaloi and Steyn, 2013). Their self-perception determines their professional destiny. Psychological factors therefore can also have an impact on women with regard to management of primary schools hence this study wished to find out the influence of psychological factors on women with regard to management of primary schools. The researchers sought to know whether psychological traits bar the female head teachers from performing school duties effectively. The majority of the teachers (87.5\%) indicated that psychological traits do not bar them from performing school duties effectively while $12.5 \%$ of them indicated that psychological traits bared them from performing school duties effectively. Guzman and Guillermo's (2007) study indicated that one of the female school heads described her metamorphosis in the course of her school leadership. She started off with a feeling of fear, which initially made her rigid to the policies in place. She subsequently learnt the art of total trust and surrender, which meant that she could then freely delegate, and rid herself of some of the school duties. Being transparent and open led to gaining the trust of many, and openness led to open lines of communication with teachers, students and parents. This is supported by Syed and Murray (2008), who also commented that women have specific attributes, characteristics and skills that are beneficial to organisations and teams. They said that the work place structures need to value the feminine attributes of nurturance and collaboration.

The researchers also got information from head on whether psychological traits hinder the female head teachers from effectively managing primary schools. The majority $(81.25 \%)$ of head teachers also indicated that psychological traits do not bar them from effectively managing the primary schools while $16.7 \%$ indicated that psychological traits do bar from effectively manage primary school schools. The results matched well with what the teachers revealed as was already indicated in Table 16. The reasons why the psychological traits do not bar them was because of long teaching experience, they are assertive, aggressive, and trained professionals hence are able to handle students well. Women have to prove themselves over and over again before they are recognised, and consequently great psychological strength, confidence and commitment is required from them to cope with the pressure (Mitroussi and Mitroussi 2009). In advancing the social cognitive theory in the study of women and leadership, it is important to learn how the socialisation process and societal expectations shape women's choices in entering leadership positions, and their experiences once they attain these positions.

In addition to the above information the female head teachers also provided information on their confidence in leadership as compared to their male counterparts. All (100.0\%) the female head teachers rated their confidence in leadership being above average as compared with their male counterparts. They consider themselves worthy to be in leadership positions. Shakeshaft (1987) as quoted by Hoff and Mitchell in 2008 suggested that women have excellent leadership skills, but often face obstacles that men may not face. Skilful school leaders influence school and classroom processes that have a direct impact on student learning. This means that female heads of schools need to be equipped with appropriate knowledge and skills through training programmes in school management and for them to gain confidence and courage for the running of day-to-day school activities (Cowie and Crawford 2008). 
Data was also collected from head teachers concerning traditional orientation. All the female head teachers indicated that traditional orientation does not work against their profession. However, Blackmore (2010) continuously raises debates on gender, culture and women in administration. Her argument focuses on the importance of women's approaches and the significance of their feminine character traits in leading which more often seem to go unnoticed. Madziyire and Mapolisa in 2012 see women's career progression as being slowed down by traditional roles. Though this was revealed by these two researches, the female head teachers under study clearly indicated that traditional orientation does not work against their profession.

\section{Becoming a head teacher}

This theme focused on the female head teacher's motivation for entering headship, the preparation received for headship, society's perception of female head teachers as well as the perceived barriers to women's participation in school leadership.

\section{Motivation to become a head teacher}

For most of these women, the suggestion for their promotion had come from other people, mostly officers in the education leadership hierarchy. This finding corresponds with an observation made in a study by Adams $\&$ Hambright (2006) that some women may not consider upper level positions on their own, and thus there existed the increased importance of well-placed suggestions by mentors. Interestingly, none of the participants in this study resisted taking up the posts when they were offered to them.

All of the participants had applied for headship and all were once deputy head teachers. Two of these women seemed to have gained confidence and started believing in their leadership capabilities during the years they had worked as deputy head teachers. A common motivation among them was their knowledge of administrative duties at a higher level. Two of them said their head teachers were away from school most of the time. They found themselves handling the head teacher's duties, and this motivated them to showcase their capabilities.

Several of the women had shown leadership qualities elsewhere, mostly in church. They also believed in their leadership capabilities as deputy head teachers. It is no wonder then that none of them had resisted when someone else commented on them as being suitable for the position of a head teacher. Another similarity is the relative degree of ease with which they had entered school leadership, as none of the women reported having experienced obstacles on their path to leadership.

\section{Preparation for headship}

Most of the female head teachers in this study had no leadership training related directly to the position of head teacher. This research study confirms (Bush, 2006), who states that in Africa, preparation and development of principals is not as pronounced and systematic as it is in the developed countries. In most cases, it is either lacking or not formal. Although three of the women had attended a primary school management course earlier in their careers, they admitted it was not a conscious effort on their part to prepare them for headship at the time. For them it was just another course that had been introduced by the ministry of education that their head teachers had nominated them to attend. They had all worked as senior teachers in their schools at that stage. They, however, said that the knowledge from the course helped them a great deal when they became heads.

All the female head teachers had attended various seminars and workshops during the course of their work. These workshops addressed specific aspects of their work, especially if it was something new the Ministry of Education or another stakeholder was introducing in the school system. The examples they gave included seminars on early reading initiatives, performance lag address programmes, gender and inclusive education, and health issues. They acknowledged that this kind of training helped them to integrate new programmes into their school systems. 
This finding illustrated that their responsibility for school duties in their work as deputies, and by means of other duties delegated to them by their head teachers, helped them in their work. Though the majority of them had not attended school management courses, they learned on the job. The participants were, however, in agreement that some form of training, specifically directed at the duties they were going to take up as head teachers, would have helped them in performing their duties more efficiently. One of the participants sums it up as follows,

'The nature and the scope of the work change as you get into administration, and I feel that some form of training beyond the orientation given by my former head teacher would have been necessary'.

The findings concurred with studies in the literature review which indicated access to leadership programmes as one of the factors that attracts women to leadership. The studies include the comments by Mitroussi and Mitroussi (2009), who noted that women need to feel well-prepared before they applied for a leadership position, and Cowie and Crawford (2008) who observed that preparation for leadership can help to develop the professional identity of aspiring female head teachers, broaden their outlook and develop confidence and self-belief.

Through interviews were conducted, the researchers also examine the society's perception of female head teachers.

\section{Society's perception of female head teachers}

Although these female head teachers did not experience obstacles at the time of their appointment, most of them felt that once in their schools, they were received into headship with some scepticism. They, nonetheless, acknowledged that with time the society accepted and respected female head teachers after they had proved themselves. Indeed, some of the schools that the researchers visited the best-performing schools in the vicinity. The female head teachers attributed the good performance to their working hard to try and prove themselves. This seem to agree with Chikwature and Oyedele (2016) who observed that women are perceived as being more likely to be collaborative in their working relationships, and tend to use democratic leadership styles and power which, in turn, contribute to achieving high levels of job satisfaction among staff members.

Another participant was of the opinion that the way women led also had something to do with the improved performance, and hence improved acceptance. She said,

'You know women are motherly, and they tend to nurture their subjects. Teachers and learners who are treated well tend to work hard because they would not want to disappoint their 'mother'.

\section{Administrative challenges}

The challenging nature of the female head teachers' jobs was compounded by some particular factors that emerged from the data, which include accountability issues, parents' grievances and expectations, time away from school, limited resources, dealing with school management committees, and dealing with difficult teachers.

\section{Accountability issues}

Primary school head teachers are the managers of the curriculum, of the people and of the resources in their respective schools. Issues of being accountable for these responsibilities kept recurring in the interviews. Most of these head teachers, as noted earlier, had not attended school management courses to prepare them for headship, and thus for their leadership roles, as a result, they found themselves feeling overwhelmed by the responsibilities. One of the female head teachers indicated, 
'Whatever happens in this school, all the questions land in my office first. If exams results are bad, I am the one to be blamed. If money is misappropriated, they will come for me first. If a child gets hurt, I will be the one to answer. Don't you think this is too much for one person?'

Yet another female head teacher concurred saying that sometimes people even referred to the school as the head teacher's school, instead of calling it by its name. She experienced cases where she got calls asking her to explain things that happened at school during her absence, even before she had a briefing with the teachers concerned. 'One is expected to have answers all the time. I only feel comfortable when I leave the school after all the teachers and pupils have left'. What this female head teacher meant by this was that she always got to school before everyone else and left school after everybody else has left. That, she said, reduced the chances of her being taken by surprise by things that happen in the school.

Although these female head teachers made use of delegation and consultation to ease their workload, they still felt overwhelmed by the fact that they were held accountable for everything that happened in the school. This research study confirms the findings in Kocabas and Karakose's (2009) study where they noted that school heads have a key role to play in managing their schools because they are accountable of everything that happens in school. The success of the school and the degree to which they reach their educational aims depend on the school head and his or her governance. On the same point, Aketch and Simatwa (2010) noted that in Zimbabwe the government and all the other stakeholders look upon the head teacher for the effective implementation of any programme introduced at primary level.

\section{The parents' grievances and expectations}

Another common theme among the participants was the dilemma they sometimes faced when handling the grievances of parents, and the high expectations these parents had from the school. All the head teachers interviewed had, at one time or another, to handle parent's grievances, some of which created a great deal of stress. It is simply not possible for the head teachers to keep all the stakeholders happy all the time and there were times when the parents left the school dissatisfied because the head teacher did not respond as they had expected.

In some cases, the grievances were directed against the teachers. The teachers are guided by a code of regulations, and the head teacher first has to ascertain if an offense was committed. Another female head indicated that some parents could not understand that the head teacher needed to listen to both sides before she could take any action, and that she was limited in her reactions by protocol. 'Some of them expect me to call in the teacher and ask and blame the teacher before them. Sometimes it is the parent who is in the wrong, usually because of not knowing the school rules.

In other cases, the grievances were against other parents. Certain disagreements that happen in the village end up in school. Sometimes the parents involved their children too much in their personal affairs. Children from such homes sometimes got involved in a fight at school, and after investigation it was found that the fight had actually started at home, necessitating the head teacher to summon the parents. This is what happened at one of these seven schools. And yet, at times the grievances were against the parents' own children. The participants felt that sometimes the parents expected too much from them, bringing to school issues that they actually had to resolve at home. One female head teacher also said that it was not unusual for a parent to come to her office with the child, expecting the head teacher to punish the child for things that the child did at home. On one occasion a parent brought her grandson to school to report to the head teacher that the child had not slept at home. Although she later took time to counsel the boy, this particular female head teacher who faced this case was of the opinion that some parents needed to exercise their authority where their children were concerned. She said, 'I find some of these parents ridiculous. Some of them do not want to take responsibility. They think all the discipline lies with the head teacher'. 
Also, one of these female head teachers whose school served mostly children from the resettlement area said when a parent wanted to enrol her child for the first time, she found herself listening to stories of broken homes, poverty, child abuse, and so on. She said that some of these experiences really weighed her down.

'I have to listen to all their stories. I am human. These stories affect me. Sometimes I spend quite some time trying to calm down a parent who finally seems to have found a person with whom to share her grief. I am not trained in counselling, but I do the best I can.'

Children from such often demonstrate emotional problems that interfered with their performance at school. Each of the head teachers had these kinds of children in their schools. As one of the head teachers commented, 'The first measure for the success of a school is performance, yet the social and emotional status of a child is also a great determinant of performance. Some people do not understand this. They expect us to perform miracles.

The grievances of parents are common in schools, contributing to the stress of the head teacher who has to work through the grievance process to reach a solution. When an offended parent comes to school, the first person who has to respond to her is the head teacher. This takes the head teacher away from her other duties and responsibilities, and which may sometimes even have an effect on her emotions. The experiences of these head teachers concur with Slater, et al.'s (2008) observation that school heads act as 'buffers', absorbing the pressure and responsibilities stemming from problems among teachers, students, parents, supervisors and the community.

\section{Time away from school}

Primary school head teachers are also classroom practitioners, and the number of lessons they take depends on the status of staffing at their schools. Several of the participants had a class to teach because of low enrolments. Four of the female head teachers had almost the same teaching load as the other teachers. One was also a class teacher, in charge of grade seven. Her absence from school to attend meetings at the education office, or networking with other stakeholders to solicit funds for their schools, meant that quite an amount of her teaching time was being used. This forced her to take extra time to cover her lessons which, at times, interfered with the children's and their own schedules. Yet, the classes had to be taught because the syllabus had to be covered, and the head teacher also knew that the other teachers were looking up to her to produce excellent results.

One of them said she missed the days when she could attend to all her lessons as scheduled. It gave her confidence for the exams because she knew she had done her work well. If her pupils did not perform well (which, ironically, rarely happened, even with her frequent absence) it always left her feeling that she had failed the learners. She wished all rural school were equipped with computers and Wi-Fi so that some of the information they received at meetings could be shared through mails, so that she did not have to do all the travelling. Although this was not a common challenge among participants in other studies reviewed, it was found to occur quite frequently among the participants in this study.

\section{Dealing with the school management committees}

Each of the schools under study has a school management committee which runs the development issues of the school in liaison with the head teacher, who is also the committee member. The committee members, who work on a voluntary basis, are elected by the parents. Although the participants appreciated the contribution of the members of the committee, they commented that sometimes there was a drag in the way things were carried out, because the committee takes time before it meets. Such a case was witnessed by the researchers in one of the schools. A meeting with the head teacher was scheduled for two o'clock because she had indicated that she had a meeting with the school management committee members at ten o'clock in the morning. By the time the researchers reached the school at half past one, the meeting had not taken place, so 
the head teacher decided to finish her meeting with the researchers first. At the end of the day the meeting with the committee members was called off as only two members had turned up.

\section{Dealing with difficult teachers}

Whether the head teacher was promoted in the school she had taught, or was transferred to another school, each of the participants experienced difficult teachers on the staff, and this posed a great challenge. The female head teachers made mention of teachers who always came to school late, who were absent without permission, and who 'were not a good example to the pupils', according to one of the head teachers. Probed further, she said she was referring to teachers who sometimes come to school intoxicated, or who smoked in the school compound, knowing too well that it was against the rules. The dilemma of dealing with some of these teachers presented itself especially if the pupils performed well in that particular teacher's class, which was sometimes the case. The dilemma arose on whether to report the teacher to the authorities and risk having him transferred which might result in lowering the school's pass rate, or simply to let him be. One of the female head teachers explained her dilemma as follows,

In administration I believe there is a code of regulations, and then there is the human face. When one is faced with a difficult teacher, you want to hope that he will change with time after being talked to. If he is a good performer, you really do not want to lose him. It is a tricky situation because, on the other hand, you also fear that he may be a bad influence on others.

A specific category of teachers who were thought to be difficult by the participants were those who had stepped down from headship as they kept undermining the school leadership, and who were reminiscing about their days as heads. Those who went back to teaching after going through interdiction were also considered to be problematic.

Having examined the administrative or institutional challenges of the women head teachers, the researchers now examines their personal or psychological challenges.

\section{Self-confidence}

From the accounts of these head teachers it was apparent that from time to time they experienced a lack of confidence in their work. For most of them this was their first time to head a school. Only one of the women worked in a school which had been headed by a female head teacher before. She reported feeling uncomfortable during the first days, and even thereafter, when they had to deal with issues that posed a dilemma. That female head teacher put it this way,

'The first time I addressed the school assembly as head of a new school I felt uneasy. I had prepared a very short speech because I felt my confidence failing. I asked for feedback from one of the teachers whom I had worked with in another school and she said that I need not have worried'.

Their responsibilities were sometimes overwhelming, and they did not always feel sure that what they were doing was the right thing. Also, one head teacher commented,

'I find myself scrutinising my reaction to situations all the time and wondering whether I handled them in the right way. I usually take time before making a decision as I pondered the best route to take. The moments just before a major decision has to be made are the most difficult time for me.

The women in the study, however, acknowledged gaining confidence and adopting coping mechanisms as time went by. They did not, though, elaborate on the coping mechanisms. Each of them said they had a higher level of confidence than when they had started working in their positions. 


\section{Balancing work and social life}

The female head teachers spoke of how their social lives had been affected by their entry into leadership. Spending many hours at school meant that part of their private lives needed adjustment. One head who worked in the same neighbourhood where she lived, explained how her religious activities have been affected. She used to attend lunch time prayers in her local church but was failing to attend due to pressure of administrative. She was deciding to quit the leadership post she was given at the church.

The way the society perceived the female head teachers also had an effect on their lives, and they had to be extra careful of how they behaved themselves socially. One shares the following,

'Being a head teacher has put me in the limelight and now more people recognise me wherever I go. I have to be a role model. I have to be mindful of the way I dress, whom I associate with and even the places I visit'.

The time-commitment of these female head teachers was incredible. They spent so much time managing school school-work and responsibilities at home that they had no time left they could call their own. This indicates that the dual role that women play will affect them irrespective of their potential and quality. Some of them said they did not have time to interact with their friends as they used to do.

Interestingly one added,

'I don't have enough time left to groom myself. Sometimes I wear the same hairstyle for days. I look at the other lady teachers with their smart hairstyles and I envy them. These days you mostly find me in the salon after hours.

The added responsibilities kept the women so busy that it affected their relationships with their friends, their religious obligations, and even the time meant for themselves.

\section{Home-work conflict}

Perhaps the one area that all the participants felt that suffered the most was their family life. The ascribed roles of women on the domestic front created a challenge where they had to balance work and home. Each of them had something to share on how their administrative duties affected their time and their relationships with their families. This is in agreement with Bush and Middlewoodin 2007 who believe that the twin demands of career and family affect both men and women, but it is the woman who most often carry the major responsibilities within the home. Although most of them reported receiving support from their family members, they felt guilty, as they felt they did not fulfil their duties as mothers and wives (for those who were not widowed) the way they wished to. They had to make sacrifices, especially in respect of their families. This was confirmed by two of them, who said they had to send their youngest children to boarding school, as they felt they were not giving them enough quality time. One of the two indicated,

'My son would get home before me, and since I am tired most of the time when I get home, I was not able to share his enthusiasm. I decided to send him to board school with the hope that I would be in a position to give him better quality time when we are both at home during the school holiday'.

Another female head teacher mentioned how her daughter was once sent home from school because her mother had failed to attend a parents' meeting. A head teachers' meeting coincided with the parents' meeting. She had chosen to attend the head teachers' meeting and visit the school the following day. 'I was left feeling as if not responsible'.

One female head teacher said she did not have the time to attend to her domestic animals as she would have liked to. 
'Although I want this leadership, I don't want to lose my status in the family. I rarely see my animals these days. It takes me one hour to get here from home and I leave the school premises very late. My husband understands me, but it leaves me feeling inadequate'.

It seemed that even as these women attended to their leadership roles, they still valued the roles they played at home. They felt as if they were not adequately performing their duties as mothers, wives and home-makers. This left them with a sense of guilt. These findings mean they all recognised child-care and family responsibilities as challenges unique to women. Knowles, et al. (2009) particularly noted that many mothers felt exhausted and overwhelmed, trying to balance paid work commitments with parenting commitments. Thus, they were psychologically, intellectually and emotionally drained.

\section{AUTHORS' CONTRIBUTIONS}

Based on the insights gained from this study, the following recommendations were made:

1. That since female head teachers were positively viewed by teachers, there is need to be given more posts of leadership in primary schools.

2. The female head teachers are effective hence they are able to achieve the goals of their respective institutions.

3. Although cultural and social barriers may interfere with the management of school affairs, there is need for female head teachers to be encouraged to achieve leadership positions since they can manage the roles of leaders. This is through mentorship.

4. The attitude toward female head teachers was good as rated by teachers hence there is need for the female head teachers to use the best leadership style that would influence positively on their positions in the school society.

5. Psychological factors do not bar female head teachers from performing in their schools. Hence there is need to have more female teachers in leadership positions.

6. The government should avail funds to schools for training and development of teachers.

7. Female head teachers should have leadership skills that would encourage them in delegation of duties to their staff, decision making and involvement of other stakeholders in the day to day running of the school.

\section{REFERENCES}

1. Adams, K. And Hambright, G. (2006). Encouraged or discouraged: women teacher leaders becoming principals. The Clearing House, 77(5):209-211.

2. Aketch, B. A. And Simatwa, EM. (2010). Opportunities and challenges for public primary school head teachers in the implementation of free primary education in Kisumu Municipality, Kenya: an analytical assessment. Educational Research and Review, 5(9):484-491.

3. Bush, T. (2014). Emotional Leadership: A viable alternative to the Bureaucratic model. Educational Management Administration and Leadership, 42(2), 163-164.

4. Busolo, J. (2007). Teachers' perception of secondary school women head teacher's leadership behaviour in Vihiga district and Kisumu city. Unpublished M. EdThesis, Kenyatta University. Nairobi. 
5. Celikten, M. (2006).A perspective on women principals in Turkey.International Journal of Leadership in Education, 8(3):207-221.

6. Chelimo, C. and Wasanju, M. (2007). Challenges faced by women in educational leadership: Problems encountered by women leaders, Moi University Eldoret.

7. Chikwature, W. and Oyedele, V. (2016). School Heads and Teachers Perceptions on the Factors Influencing Pass Rate at Ordinary Level in Mutasa District of Manicaland. Greener Journal of Educational Research, 6(1):005-019

8. Cowie, M. \& Crawford, M. (2008). 'Being' a new principal in Scotland.Journal of Educational Administration, 46(6):676-689.

9. Grant, J. (2008). Women as managers: what they can offer to organisations. Warner books: New York.

10. Guzman, AB. \& Guillermo, M. (2007). The serendipity of principalship: meaning-making of a Filipino secondary school principal. Asia Pacific Education Review, 8(2)216-233.

11. Hoff, H. and Mitchell, S. (2008). The lady vanishes: some thoughts on women and leadership. Journal of Organizational Change Management, 20(2):198-208.

12. Hoy, W. and Miskel, C. (2009). Educational administration: Theory, research and Practice (5th Ed.). New York: Random House.

13. Kamau, W. (2006). Problems faced by female head teachers in the administration of secondary schools in Thika district. Unpublished M. Ed project, Kenyatta University Nairobi.

14. Khumalo, S. (2006). Challenges Faced Women as School Managers in Primary Schools in Warmbaths Area.Magister Technologia Mini Thesis, Unpublished. Pretoria: Tshwane University of Technology.

15. Knowles, M., Nieuwenhuis, J. \&Smit, B. (2009). A narrative analysis of educators lived experiences of motherhood and teaching. South African Journal of Education, 29:333-343.

16. Kocabas, I. And Karakose, T. (2009). Ethics in school administration. African Journal of Business Management, 3(4):126-130.

17. Madziyire, N.and Mapolisa, T. (2012). Female leadership dilemmas in primary schools: A case study of 18 primary schools in Kambuzuma, Warren Park and Kuwadzana areas of Harare province in Zimbabwe. International Journal of Social Science and Education, 2(3): 447-460.

18. Mitroussi, A. \&Mitroussi, K. 2009.Female educational leadership in the UK and Greece.Gender in Management: An International Journal, 24 (7): 505-522.

19. Mutopa, S., Maphosa, C., \& Shumba, A. (2011). School management and teaching: The dilemma ofteaching school heads in Zimbabwean secondary schools. Journal of Educational Studies,5 (2), 146164.

20. Oyedele V and Chikwature W (2016). The Obligation of School Development Committees in Teacher Retention in Buhera District Primary Schools in Manicaland Province, Zimbabwe. Greener Journal of Educational Research, 6(2): 034-043,

21. Parsaloi, M. W.; Steyn, G. M. (2013). Gender \& Behaviour, Academic journal article Vol. 11, No. 1 
22. Pont, B., Nusche, D. \& Moorman, H. (2008). Improving school leadership, Volume 1: policy and practice. Paris: OECD.

23. Slater, CL., Garcia, GL. \&Gorosave, GL. (2008). Challenges of a successful first year principal in Mexico Journal of Education Administration, 46(6):702-714.

24. Smyth, A. (2009). Sharpening leadership skills: connecting with the sisters. Diverse Issues in Higher Education. 26(2)7-10.

25. Syed, J. \& Murray, PA. (2008). A cultural feminist approach towards managing diversity in top management teams. Journal of Equal Opportunities International, 27(5):413-432.

26. Wolfram, D. 2007. Female superintendents: perceived barriers and successful strategies used to attain the superintendence in California. Unpublished Deed. -thesis. California: University of the Pacific. 